https://doi.org/10.15407/ujpe65.8.701

T.V. TROPIN,${ }^{1}$ N. JARGALAN,${ }^{2}$ M.V. AVDEEV,${ }^{1}$ V.L. AKSENOV ${ }^{1}$

1 Joint Institute for Nuclear Research

(6, Joliot-Curie, Dubna 141980,Russia; e-mail: ttv@jinr.ru)

2 Institute of Physics and Technology, Mongolian Academy of Sciences

(54B, Enkhtaivan Ave., Ulaanbaatar 210651, Mongolia)

\title{
INVESTIGATIONS OF THE KINETICS OF CLUSTER GROWTH IN FULLERENE $\mathrm{C}_{60}$ SOLUTIONS
}

\begin{abstract}
Fullerenes tend to form clusters in different solutions. In this work, a brief survey and some results in the field of investigations of the structure and kinetics of clusters growing in $C_{60}$ solutions are presented. The general character of this phenomenon for fullerenes is emphasized, and the considerations of mechanisms responsible for the formation and growth of clusters are discussed. We distinguish different types of fullerene solvents by the aggregation mechanism. The kinetics of cluster growth measured via the dynamic light scattering is presented. The complicated structure of clusters in different solutions is briefly discussed.

Keywords: fullerene, fullerene solutions, aggregation, cluster growth, kinetics, dynamic light scattering.
\end{abstract}

\section{Introduction}

Fullerenes in solutions present a very interesting system for investigations [1-5]. In fact, a distinctive, in comparison to other allotropic forms of carbon, solubility of fullerenes has been revealed right after their discovery. Up to now, the fullerene solutions remain a quite "hot" topic in the scientific community. This is both due to perspectives connected with the applications, and a variety of effects observed in these systems. The effect central for the present work is the formation and growth of clusters in $\mathrm{C}_{60}$ solutions $[2,3,6]$. In addition, the anomalous temperature dependence of the solubility [7], solvatochromic effects [8], and formation of complexes can be mentioned.

The first indications of the formation and growth of clusters in fullerene solutions date back to 1993 1994 [9-12]. The slow growth of comparatively large (hundreds of nanometers) fullerene clusters composed of $\mathrm{C}_{60}$ or $\mathrm{C}_{70}$ macromolecules was reported. The re-

(C) T.V. TROPIN, N. JARGALAN, M.V. AVDEEV, V.L. AKSENOV, 2020

ISSN 2071-0194. Ukr. J. Phys. 2020. Vol. 65, No. 8 versible nature of aggregation was noted for low-polar organic solvents, while, as it seems, this is not the case for polar liquids and their binary mixtures. During next 25 years, numerous research articles were published on the subject. Contradictory results are quite regular, specifically in the case of low-polar fullerene solutions. A highly qualitative survey was given in 2011 in [2], and the further updates can be found in $[3,6,13,14]$. The structure and kinetics of growth of fullerene clusters in solutions have been studied by a variety of experimental methods, including small-angle X-ray and neutron scattering (SAXS and SANS), dynamic light scattering (DLS), static light scattering, UV-Vis spectrophotometry, electron and atomic force microscopies.

Presently, based on the character of the fullerene aggregation, several different classes of fullerene solutions can be distinguished [6]. The first class consists of solutions in low-polar liquids. In these systems, the formation of clusters depends on the preparation conditions (equilibrium dissolution, mechanical stirring, ultrasound treatment), temperature, concentration, 


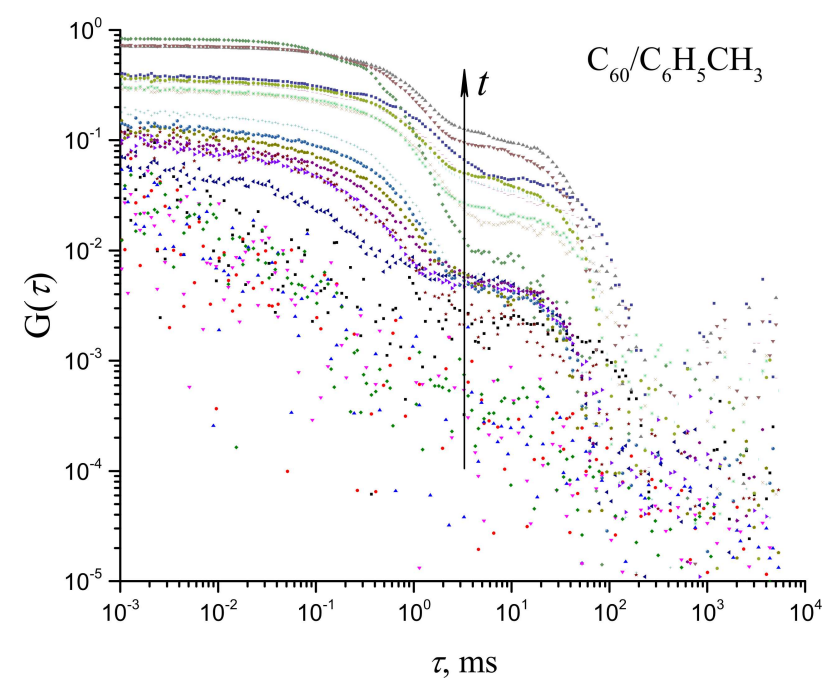

Fig. 1. Evolution of the DLS correlation function of a $\mathrm{C}_{60} /$ toluene solution with time. First measurements were done after the exposure to light, last measurements - after several days

and other factors. The representative solvents are toluene [15-20], benzene [10,11], carbon disulfide [2123], chlorobenzene [20]. Specific conditions for obtaining the stable molecular solutions in these systems are presently known. The second class of fullerene solutions consists of polar solvents. The solubility in these liquids is in general lower than in low-polar solvents. The lyophobic character of the solubility of fullerenes results in the formation of stable aggregates in these systems $[24,25]$. Investigations of the effect of solvent polarity (using binary mixtures) reveals a certain transitional value of the dielectric permittivity of a solvent [26]. A subclass of these systems can be distinguished for the nitrogen-containing solvents such as N-methyl-pyrrolidone (NMP) [27-30] and pyridine [8]. The formation of donor-acceptor type complexes between fullerene and solvent molecules takes place [30-32], and a peculiar transition from a molecular to a stable colloidal solution, accompanied by the color change, can be observed. The third class consists of colloidal aqueous solutions of fullerenes. While $\mathrm{C}_{60}$ is a hydrophobic molecule, several procedures for obtaining their water dispersions are known [3335 . These solutions remain actual due to certain perspectives of their biological applications; thus, additional structural studies took place [36-40].

In the present work, being a continuation of some of our recent researches of the formation and growth of clusters in fullerene solutions, we present new results obtained via dynamic light scattering measurements on low-polar (toluene, benzene) and polar (NMP) fullerene solutions. The paper is organized as follows: in the next section, the results of investigations of the kinetics of cluster growth in both low-polar and polar fullerene solutions are presented. In Section 3, we discuss the obtained results and the possibility to describe the kinetics via a system of kinetic equations. Conclusions finalize the article.

\section{Experimental Part}

The low-polar fullerene $\mathrm{C}_{60} / \mathrm{C}_{70}$ solutions were widely studied for the last 20-30 years using different methods. Most of the contradictory results regarding the formation and growth of clusters were obtained for these solutions, due to the effect of external preparation conditions on the behavior of systems $[6,15,20,21]$.

Our recent investigations were devoted both to the kinetics of dissolution and aggregation of fullerenes in low-polar solutions and the structural features of the clusters that are formed [30, 41, 42]. In [41], it was shown that the kinetics of solubility (measured by UV-Vis) of fullerenes can be well described by the Noyes-Whitney equation. Different temperatures and preparation conditions were investigated. The kinetic rate constants were obtained for their use in a theoretical work and further investigations.

Recently, we have performed investigations of the kinetics of formation and growth of clusters in similar solutions by the DLS method (using a Photocor Compact $\mathrm{Z}$ instrument). Measurements were made on several samples of $\mathrm{C}_{60}$ dissolved in benzene and toluene. In agreement with results of works $[10,11,15]$, we obtained that the cluster formation and growth doesn't start, if the sample is kept in a sealed vial in dark. The molecular solution is stable under these conditions for many days. However, if a sufficient amount of oxygen is present in the solvent, or if the solution is exposed to light, the aggregation starts. An example of the time evolution of the DLS correlation function $(\mathrm{CF}, G(\tau)=\langle I(t) I(t+\tau)\rangle$, where $I(t)$ is the intensity of scattered light) is presented in Fig. 1. A clear increase of the light scattering by two populations of clusters is observed.

In the case of monodisperse particles in a solution, the DLS correlation function is expressed by

$G(\tau)=A\left(1+B e^{-D q^{2} \tau}\right), \quad q=\frac{4 \pi n}{\lambda} \sin \frac{\theta}{2}$, 
where $A$ and $B$ are the parameters, $\theta$ is a scattering angle, $D$ is the diffusion coefficient, $q$ is the scattering wave vector, $n$ - refraction index of the solvent, and $\lambda$-wavelength of light. The diffusion coefficient obtained from the measurements is used to obtain the hydrodynamic radius of particles via the StokesEinstein equation

$r_{h}=\frac{k_{\mathrm{B}} T}{6 \pi \eta D}$,

where $T$ is the temperature, and $\eta$ is the viscosity.

In the case of polydisperse particles, the size distribution in a solution, Eq. (1), must be updated to:

$G(\tau)=A\left[1+\sum_{i} B_{i} e^{-D_{i} q^{2} \tau}\right]$.

The approximation of the measured correlation functions with the use of (3) gives the cluster size distribution functions. Considering $G(\tau)$ (Fig. 1) for $\mathrm{C}_{60}$ solutions in low-polar liquids, it is qualitatively sufficient to use only a few terms in the sum in (3). We have used two terms for the fitting to characterize the populations of clusters significantly different by sizes. The growth of the pre-exponential parameter $B_{i}$ for each population characterizes the growth of its relative fraction in a solution, while $D_{i}$ is used to estimate the average radius of clusters. The growing second plateau of $G(\tau)$ corresponds to cluster sizes of several micrometers. While a general trend of their growth is also seen in Fig. 1 (shift of the plateau toward longer $\tau$ ), a monotonic function is generally not obtained, probably due to low values of the correlation function. On the other hand, reasonable results for the growth of clusters with sizes 100-200 nm were obtained (Fig. 2).

For a supersaturated $\mathrm{C}_{60}$ /toluene solution, we observed a two-step character of the growth of clusters, while this was not the case for a usual unsaturated system. For $\mathrm{C}_{60}$ /benzene solutions, we observed the simultaneous growth of 100-200 nm clusters and micrometer-sized clusters. The growth of micrometer-sized clusters in toluene does not follow a monotonic character in our experiments and is not presented here. Probably, those clusters are less stable. In addition, they are larger than those in benzene and thus may sediment in the solution. As was already mentioned, the aggregation in both systems
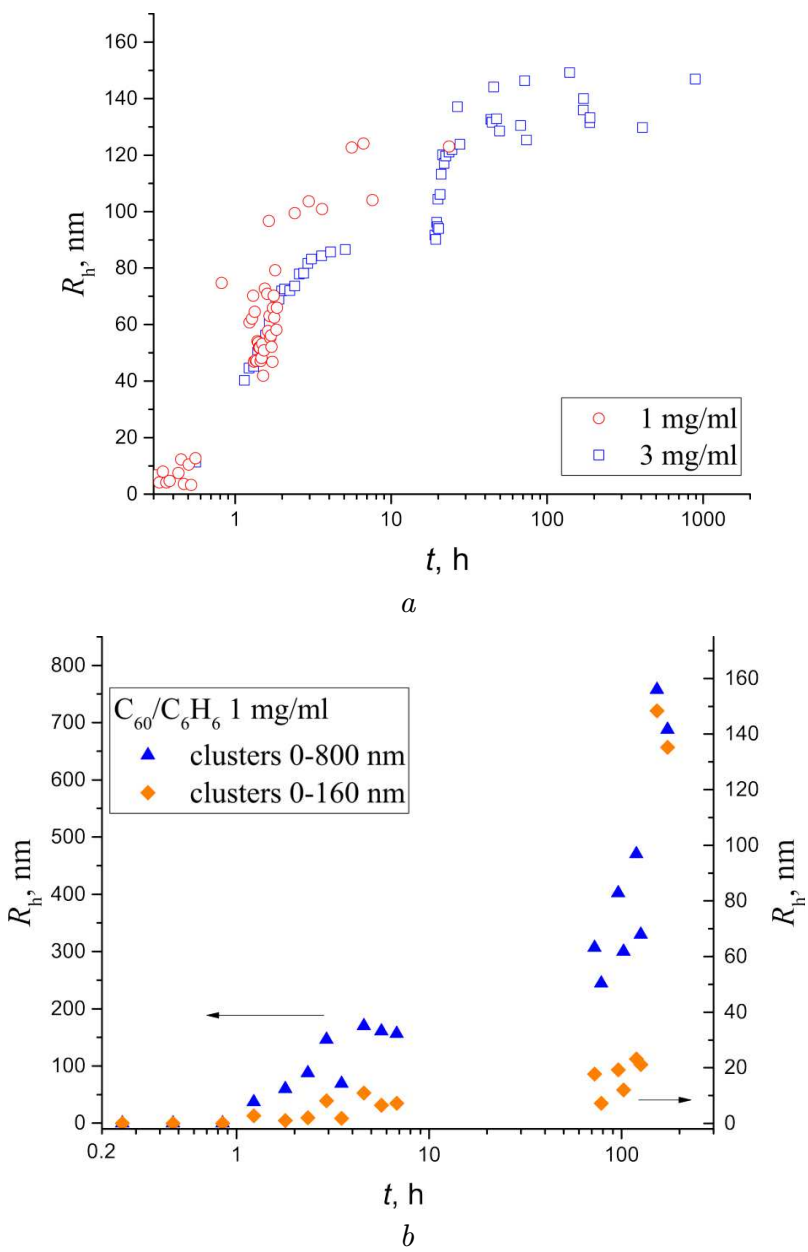

Fig. 2. Evolution of the average hydrodynamic radius of clusters in two $\mathrm{C}_{60}$ /toluene solutions after the photooxidation $(a)$. Evolution of the average $R_{h}$ for two populations in $\mathrm{C}_{60}$ /benzene solution $(b)$

starts only after the solution is subjected to light and a sufficient amount of air.

Unlike low-polar solutions, the formation and growth of clusters in polar liquids starts immediately after the fullerene dissolution start. This growth cannot be suppressed by external conditions $[24,26$, 43]. A specific subgroup (or even a separate group) is the nitrogen-containing solvents, e.g., N-methylpyrrolidone and pyridine, for which researchers have reported the initial molecular state of a solution $[27,31$, 44] (by UV-Vis spectrum) which evolved to the stable colloidal state. The character of the aggregation is reversible only at the early stages of growth. Moreover, the drying of the dispersion does not pro- 


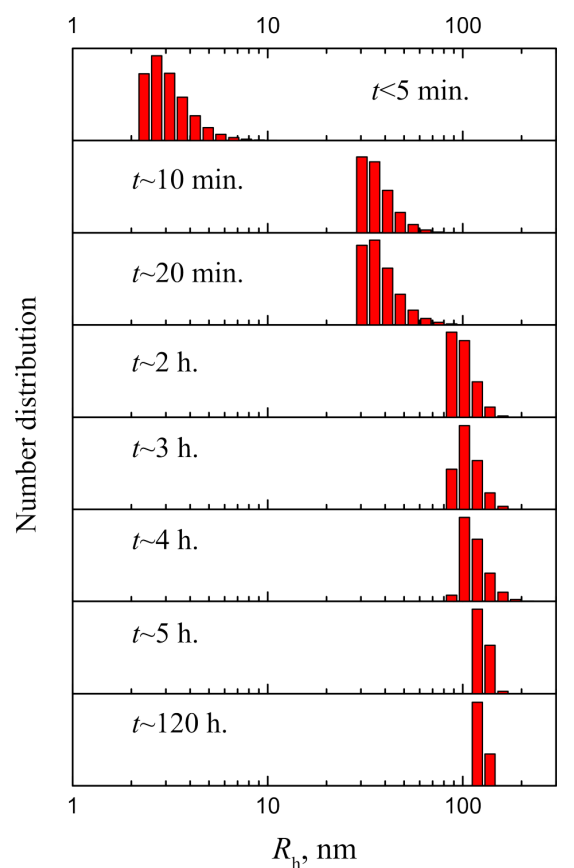

Fig. 3. Evolution of the cluster-size distribution function for a $\mathrm{C}_{60} / \mathrm{NMP}$ solution $(c \sim 1 \mathrm{mg} / \mathrm{ml})$. Time after the fullerene dissolution start is indicated for each measurement

duce crystal fullerene soot, but an amorphous substance, which cannot be easily redissolved in fullerene solvents. This fact is an additional separate indication of the formation of complexes between fullerene and solvent molecules, which has been proved by experiments and calculations [27, 30, 32]. Using the $\mathrm{UV}-\mathrm{V}$ is method we have recently estimated the rate of formation of these complexes, as well as its dependence on the temperature and preparation conditions of a solution [42, 45] (the average value is $10^{-3} \mathrm{~s}^{-1}$ ). Measuring the kinetics of cluster growth via DLS is more difficult than for low-polar solvents, because, as it seems, it is hard to prevent the formation of clusters that starts simultaneously with the dissolution of fullerene. The usual scheme, consisting of the filtration and measurements following the dissolution stage, is not applicable. Thus, the investigations have to be performed also during the dissolution stage. The results for a saturated $\mathrm{C}_{60} / \mathrm{NMP}$ solution $(c \sim 1 \mathrm{mg} / \mathrm{ml})$ are presented in form of a series of cluster-size distribution functions in Fig. 3. These results are in line with measurements of the aggregation kinetics in toluene/NMP mixtures [28,46,47]. Within the first $1-2 \mathrm{~h}$, big clusters of fullerene were formed in the liquid (compare to Fig. 2, b). A relative thinning of the cluster size distribution function occurs at the later stages of cluster growth.

\section{Discussion of Results}

The results obtained in this work, together with our $\mathrm{UV}-\mathrm{V}$ is measurements and other investigations [10, $11,15,28,29,46]$, give a general picture of the kinetics of processes occurring in fullerene low-polar and polar nitrogen-containing solutions. Clusters grow within first few hours in the systems studied. In low-polar solutions, the process seems to be slower, than in polar NMP.

There is a general difference between the two types of fullerene solutions. In the studied low-polar solutions, one can keep the molecular solution stable for a long period (days, weeks). We extend this observation and suppose that this is the case for most of the lowpolar liquids. For example, we have observed at least a similar behavior for the chlorobenzene solvent. This molecular state, in the absence of light and oxygen in the solvent, can be considered a thermodynamically equilibrium state. When we subject the sample to light (daylight or other source), photooxidation reactions may occur $[11,15]$. The attractive forces between fullerene oxides and fullerene molecules in the solvent are supposed to be strong enough to start the aggregation [15]. The molecular solution is no longer an equilibrium state of the evolved system, and the transition to the cluster state of fullerene molecules in the liquid occurs. On the other hand, in polar fullerene solutions, the colloidal state is an initially attainable equilibrium state. Free $\mathrm{C}_{60}$ molecules in a solution are in a sort of transient state between solid crystals and clusters. The question of the reason for the stabilization of growing clusters is another thing to compare these two systems. For polar fullerene solutions, a number of measurements show the existence of a surface charge on the clusters [14, 25, 48], an expected thing for polar liquids. The nature of the stabilization of clusters in low-polar solutions is questionable. Whether a mechanism similar to that in polar liquids or some different process takes place is to be found out in a future research.

Different research groups investigated the structure of the clusters formed in these systems [15, 19$21,30,47,49]$. X-ray and neutron small-angle scattering prove as invaluable techniques, providing new 
insights into the structure of $1-100 \mathrm{~nm}$-sized aggregates in these systems. Unlike electron microscopy, which requires the solvent evaporation, the measurements are performed directly on a liquid sample. On the other hand, the cluster sizes well above $100 \mathrm{~nm}$ are outside the registration range of this method. The existing larger clusters were registered by DLS for several solvents via the static light scattering $[15,20]$ and TEM or AFM [19] in toluene. A complex structure of aggregates exists. The primary units are a few nanometer-sized dense particle aggregates forming two- or even three-level less dense structures. Similar structures are formed in an NMP solvent, where we observed the slow growth of primary units [30] during first three weeks. In other words, the restructuring of aggregates is slowly proceeding.

The description of the kinetics of cluster formation and growth, based on the theory of nucleation, was developed in Refs. [50-55]. The approach is based on the numerical solution of the following system of kinetic equations for the evolution of the cluster-size distribution function, $f(n, t)$, where $n$ is the number of fullerene molecules in a cluster:

$$
\begin{aligned}
& \frac{\partial f(n, t)}{\partial t}=w_{n-1, n}^{(+)} f(n-1, t)+w_{n+1, n}^{(-)} f(n+1, t)- \\
& -w_{n, n+1}^{(+)} f(n, t)-w_{n, n-1}^{(-)} f(n, t)
\end{aligned}
$$

where $f(n, t)$ is the number concentration of clusters, $w_{n, n+1}^{(+)}$is the probability for the cluster composed of $n$ molecules to attach one additional monomer (single molecule) per time unit, and $w_{n, n-1}^{(-)}$is, on the opposite, the probability for a cluster to detach a single molecule. These equations were applied to describe the cluster formation and growth in fullerene solutions. It was shown that the liquid drop model is not appropriate in this case, and certain modifications were considered $[50,51]$. This approach has to be modified further to account for the complex structure of aggregates formed both in low-polar and polar fullerene solutions. For polar solutions, we considered theoretically the possible effects of the formation of donor-acceptor complexes at the fullerene aggregation $[52,54]$, with confining the cluster growth being a hypothesis. Some recent investigations rise questions on this issue: the temporal solvatochromic effect associated with the complex formation seems to be detached from the cluster growth. It still may be the case that the formation of shells of complexes around

ISSN 2071-0194. Ukr. J. Phys. 2020. Vol. 65, No. 8 the clusters in nitrogen-containing solvents confines their growth. But, in comparison to other polar solvents, it is not a necessary interaction to stabilize aggregates. On the other hand, in low-polar solvent, the new hypothesis regarding the general role of fullerene oxides in the cluster formation should be also introduced into the theory. A model supposition of the additional component appearing in a solution (fullerene oxides) will be considered in a future research.

Equations of the type (4) should be used to describe the formation of dense primary clusters with the sizes up to 10-20 nm (for NMP solvent [30]) or a few nanometers (for low-polar solvents $[30,47]$ ). The formation of these clusters is appropriately described by the adding / detaching of single $\mathrm{C}_{60}$ molecules. On the other hand, as it seems to be the case from structural investigations, in a further growth, the clustercluster aggregation processes must be taken into account. The kinetic equations should be modified in this case:

$$
\begin{aligned}
& \frac{d f(n, t)}{d t}=\frac{1}{2} \sum_{m=1}^{n-1} \alpha_{m, n-m} \beta_{m, n-m} f(m, t) f(n-m, t)- \\
& -\sum_{m=1}^{n_{\max }} \alpha_{n m} \beta_{n m} f(n, t) f(m, t)-S_{n} f(n, t)+ \\
& +\sum_{m=n+1}^{n_{\max }} \Gamma_{m n} S_{m} f(m, t),
\end{aligned}
$$

where $\alpha_{n m}$ and $\beta_{n m}$ are the effectiveness and frequency of particle collisions (depending on their sizes $n$ and $m), S_{n}$ is the rate of decay of clusters, and $\Gamma_{m n}$ is the distribution function for the decay. The $\alpha_{n m}$ parameter defines the number of particle collisions resulting in their aggregation. The joint application of Eqs. (4) and (5) is expected to provide the overall evolution of a cluster state of fullerenes in solutions with the correct interpretation of the current knowledge on the structure of aggregates.

\section{Conclusions}

The general tendency of fullerene $\mathrm{C}_{60}$ to form clusters in different solutions is a well-known feature for almost 30 years $[3,6,11]$. In most solvents, a stable cluster state of fullerenes is reached with time and under certain conditions. In low-polar liquids, the light and oxygen are required to initiate the formation of clusters, while the aggregation starts already at the dissolution stage in polar solvents. Consequent measurements using light scattering methods 
allow following the kinetics of formation and growth of clusters in these systems. The clusters grow within first few hours after the aggregation starts. The further stages, taking longer time, are connected with a slower growth and restructuring. Regarding the structural investigations of clusters in different media, small-angle scattering techniques provide valuable information. It is now acknowledged $[30,36,47]$ that a two- or three-level structure of clusters exists. The developed theoretical description $[52,56]$ treats clusters as homogeneous structures and, while the dense or loose structures can be introduced easily, requires sufficient further efforts to account for different regimes of aggregation. These approaches are also expected to be further applied to another topics such as the clusters of fullerenes in the binary mixtures of polar/nonpolar or aqueous solvents $[8,14,57,58]$. Finally, we would like to note again that the aqueous solutions of fullerenes present an interesting and actual system. Similar structural and important biophysical investigations take place [59-61]. The connection with other fullerene solutions is emphasized, for example, in $[53,62]$, due to the applicability of $\mathrm{C}_{60} / \mathrm{C}_{70}$ solutions in NMP for the transition to aqueous fullerene dispersions.

This work was supported by the RFBR Project \#17-52-44024 Mong_a. The DLS study was partially supported by JINR-Romania and JINR-Czech Republic grants, 2019-2020. The support is gratefully acknowledged.

1. R.S. Ruoff, S.T. Doris, R. Malhotra, D.C. Lorents. Solubility of fullerene $\left(\mathrm{C}_{6} 0\right)$ in a variety of solvents. J. Phys. Chem. 97, 3379 (1993).

2. N.O. Mchedlov-Petrossyan. Fullerenes in molecular liquids. Solutions in "good" solvents: Another view. J. Mol. Liq. 161, 12 (2011).

3. N.O. Mchedlov-Petrossyan. Fullerenes in liquid media: An unsettling intrusion into the solution chemistry. Chem. Rev. 113, 5149 (2013).

4. V.N. Bezmel'nitsyn, A.V. Eletskii, M.V. Okun'. Fullerenes in solutions. Uspekhi Fiz. Nauk. 168, 1195 (1998).

5. M.V. Korobov, A.L. Smith. Solubility of fullerenes. In Fullerenes Chemistry, Physics and Technology. Edited by K.M. Kadish, R.S. Ruoff, (Wiley, 2000), Chap. 2.

6. M.V. Avdeev, V.L. Aksenov, T.V. Tropin. Models of cluster formation in solutions of fullerenes. Russ. J. Phys. Chem. A. 84, 1273 (2010).

7. R.S. Ruoff, R. Malhotra, D.L. Huestis, D.S. Tse, D.C. Lorents. Anomalous solubility behaviour of $\mathrm{C}_{60}$. Nature 362, 140 (1993).
8. A. Mrzel, A. Mertelj, A. Omerzu, M. Copic, D. Mihailovic. Investigation of encapsulation and solvatochromism of fullerenes in binary solvent mixtures. J. Phys. Chem. B 103, 11256 (1999).

9. Y.-P. Sun, C.E. Bunker. $\mathrm{C}_{70}$ in solvent mixtures. Nature 365, 398 (1993).

10. Q. Ying, J. Marecek, B. Chu. Solution behavior of buckminsterfullerene $\left(\mathrm{C}_{60}\right)$ in benzene. J. Chem. Phys. 101, 2665 (1994).

11. Q. Ying, J. Marecek, B. Chu. Slow aggregation of buckminsterfullerene $\left(\mathrm{C}_{60}\right)$ in benzene solution. Chem. Phys. Lett. 219, 214 (1994).

12. R.V. Honeychuck, T.W. Cruger, J. Milliken. Molecular weight of $\mathrm{C}_{60}$ in solution by vapor pressure osmometry. J. Am. Chem. Soc. 115, 3034 (1993).

13. N.O. Mchedlov-Petrossyan, V.K. Klochkov, G.V. Andrievsky. Colloidal dispersions of fullerene $\mathrm{C}_{60}$ in water: some properties and regularities of coagulation by electrolytes. J. Chem. Soc. Faraday Trans. 93, 4343 (1997).

14. N.O. Mchedlov-Petrossyan, N.N. Kamneva, Y.T.M. AlShuuchi, A.I. Marynin, S.V. Shekhovtsov. The peculiar behavior of fullerene $\mathrm{C}_{60}$ in mixtures of "good" and polar solvents: Colloidal particles in the toluene-methanol mixtures and some other systems. Colloids Surf. A. Physicochem. Eng. Asp. 509, 631 (2016).

15. R. Dattani, K.F. Gibson, S. Few, A.J. Borg, P.A. DiMaggio, J. Nelson, S.G. Kazarian, J.T. Cabral. Fullerene oxidation and clustering in solution induced by light. J. Colloid Interface Sci. 446, 24 (2015).

16. T. Tomiyama, S. Uchiyama, H. Shinohara. Solubility and partial specific volumes of $\mathrm{C}_{60}$ and $\mathrm{C}_{70}$. Chem. Phys. Lett. 264, 143 (1997).

17. I.I. Adamenko, L.A. Bulavin, K.O. Moroz, Y.I. Prylutskyy, P. Scharff. Equation of state for $\mathrm{C}_{60}$ toluene solution. J. Mol. Liq. 105, 149 (2003).

18. L.A. Bulavin, I.I. Adamenko, V.M. Yashchuk, T.Y. Ogul'chansky, Y.I. Prylutskyy, S.S. Durov, P. Scharff. Selforganization $\mathrm{C}_{60}$ nanoparticles in toluene solution. J. Mol. Liq. 93, 187 (2001).

19. U. Makhmanov, O. Ismailova, A. Kokhkharov, E. Zakhidov, S. Bakhramov. Features of self-aggregation of $\mathrm{C}_{60}$ molecules in toluene prepared by different methods. Phys. Lett. A. 380, 2081 (2016).

20. R.H. Guo, C.C. Hua, P.C. Lin, T.Y. Wang, S.A. Chen. Mesoscale aggregation properties of $\mathrm{C}_{60}$ in toluene and chlorobenzene. Soft Matter 12, 6300 (2016).

21. M.V. Avdeev, T.V. Tropin, I.A. Bodnarchuk, S.P. Yaradaikin, L. Rosta, V.L. Aksenov, L.A. Bulavin. On structural features of fullerene $\mathrm{C}_{60}$ dissolved in carbon disulfide: complementary study by small-angle neutron scattering and molecular dynamic simulations. J. Chem. Phys. 132, 164515 (2010).

22. K.A. Affholter, S.J. Henderson, G.D. Wignall, G.J. Bunick, R.E. Haufler, R.N. Compton. Structural characterization of $\mathrm{C}_{60}$ and $\mathrm{C}_{70}$ fullerenes by small-angle neutron scattering. J. Chem. Phys. 99, 9224 (1993).

ISSN 2071-0194. Ukr. J. Phys. 2020. Vol. 65, No. 8 
23. A.D. Bokare, A. Patnaik. Microscopic diffusion model applied to $\mathrm{C}_{60}$ fullerene fractals in carbon disulphide solution. J. Chem. Phys. 119, 4529 (2003).

24. S. Nath, H. Pal, D.K. Palit, A.V. Sapre, J.P. Mittal. Aggregation of fullerene, $\mathrm{C}_{60}$, in benzonitrile. J. Phys. Chem. B. 102, 10158 (1998).

25. N.O. Mchedlov-Petrossyan, N.N. Kamneva, Y.T.M. AlShuuchi, A.I. Marynin, O.S. Zozulia. Formation and ageing of the fullerene $\mathrm{C}_{60}$ colloids in polar organic solvents. J. Mol. Liq. 235, 98 (2017).

26. S. Nath, H. Pal, A.V. Sapre. Effect of solvent polarity on the aggregation of $\mathrm{C}_{60}$. Chem. Phys. Lett. 327, 143 (2000).

27. N.P. Yevlampieva, Y.F. Biryulin, E.Y. Melenevskaja, V.N. Zgonnik, E.I. Rjumtsev. Aggregation of fullerene $\mathrm{C}_{60}$ in N-methylpyrrolidone. Colloids Surfaces A Physicochem. Eng. Asp. 209, 167 (2002).

28. M. Alf'e, B. Apicella, R. Barbella, A. Bruno, A. Ciajolo. Aggregation and interactions of $\mathrm{C}_{60}$ and $\mathrm{C}_{70}$ fullerenes in neat N-methylpyrrolidinone and in N-methylpyrrolidinone/toluene mixtures. Chem. Phys. Lett. 405, 193 (2005).

29. O.A. Kyzyma, M.V. Korobov, M.V. Avdeev, V.M. Garamus, V.I. Petrenko, V.L. Aksenov, L.A. Bulavin. Solvatochromism and fullerene cluster formation in $\mathrm{C}_{60} / \mathrm{N}-\mathrm{me}-$ thyl-2-pyrrolidone. Fullerenes, Nanotub. Carbon Nanostruct. 18, 458 (2010).

30. S.V. Snegir, T.V. Tropin, O.A. Kyzyma, M.O. Kuzmenko, V.I. Petrenko, V.M. Garamus, M.V. Korobov, M.V. Avdeev, L.A. Bulavin. On a specific state of $\mathrm{C}_{60}$ fullerene in N-methyl-2-pyrrolidone solution: Mass spectrometric study. Appl. Surf. Sci. 481, 1566 (2019).

31. O.A. Kyzyma, M.V. Korobov, M.V. Avdeev, V.M. Garamus, S.V. Snegir, V.I. Petrenko, V.L. Aksenov, L.A. Bulavin. Aggregate development in $\mathrm{C}_{60} / \mathrm{N}$-methyl-2-pyrrolidone solution and its mixture with water as revealed by extraction and mass spectroscopy. Chem. Phys. Lett. 493, 103 (2010).

32. O.B. Karpenko, V.V. Trachevskij, O.V. Filonenko, V.V. Lobanov, M.V. Avdeev, T.V. Tropin, O.A. Kyzyma, S.V. Snegir. NMR study of non-equilibrium state of fullerene $\mathrm{C}_{60}$ in N-methyl-2-pyrrolidone. Ukr. J. Phys. 57, 860 (2012).

33. G.V. Andrievsky, M.V. Kosevich, O.M. Vovk, V.S. Shelkovsky, L.A. Vashchenko. On the production of an aqueous colloidal solution of fullerenes. J. Chem. Soc. Chem. Commun. 12, 1281 (1995)

34. J.A. Brant, J. Labille, J.-Y. Bottero, M.R. Wiesner. Characterizing the impact of preparation method on fullerene cluster structure and chemistry. Langmuir 22, 3878 (2006).

35. E.A. Kyzyma, A.A. Tomchuk, L.A. Bulavin, V.I. Petrenko, L. Almasy, M.V. Korobov, D.S. Volkov, I.V. Mikheev, I.V. Koshlan, N.A. Koshlan, M.V. Avdeev, V.L. Aksenov. Structure and toxicity of aqueous fullerene $\mathrm{C}_{60}$ solutions. J. Surf. Investig. X-Ray, Synchrotron Neutron Tech. 9, 1 (2015).

36. Y.I. Prylutskyy, V.I. Petrenko, O.I. Ivankov, O.A. Kyzyma, L.A. Bulavin, O.O. Litsis, M.P. Evstigneev, V.V. Che- repanov, A.G. Naumovets, U. Ritter. On the origin of $\mathrm{C}_{60}$ fullerene solubility in aqueous solution. Langmuir 30, 3967 (2014).

37. Y.I. Prylutskyy, M.P. Evstigneev, V.V. Cherepanov, O.A. Kyzyma, L.A. Bulavin, N.A. Davidenko, P. Scharff. Structural organization of $\mathrm{C}_{60}$ fullerene, doxorubicin, and their complex in physiological solution as promising antitumor agents. J. Nanoparticle Res. 17, 45 (2015).

38. A.O. Khokhryakov, M.V. Avdeev, V.L. Aksenov, L.A. Bulavin. Structural organization of colloidal solution of fullerene $\mathrm{C}_{60}$ in water by data of small angle neutron scattering. J. Mol. Liq. 127, 73 (2006).

39. L.A. Bulavin, I. Adamenko, Y. Prylutskyy, S. Durov, A. Graja, A. Bogucki, P. Scharff. Structure of fullerene $\mathrm{C}_{60}$ in aqueous solution. Phys. Chem. Chem. Phys. 2, 1627 (2000).

40. Y.I. Prylutskyy, V.V. Cherepanov, M.P. Evstigneev, O.A. Kyzyma, V.I. Petrenko, V.I. Styopkin, L.A. Bulavin, N.A. Davidenko, D. Wyrzykowski, A. Woziwodzka, J. Piosik, R. Kazmierkiewicz, U. Ritter. Structural selforganization of $\mathrm{C}_{60}$ and cisplatin in physiological solution. Phys. Chem. Chem. Phys. 17, 26084 (2015).

41. N. Jargalan, T.V. Tropin, M.V. Avdeev, V.L. Aksenov. Investigation of the dissolution kinetics of fullerene $\mathrm{C}_{60}$ in solvents with different polarities by UV-Vis spectroscopy. J. Surf. Investig. X-Ray, Synchrotron Neutron Tech. 9, 12 (2015).

42. T.V. Tropin, M.V. Avdeev, N. Jargalan, M.O. Kuzmenko, V.L. Aksenov. Kinetics of cluster growth in fullerene solutions of different polarity. Mod. Probl. Phys. Liq. Syst. 249 (2019).

43. S. Nath, H. Pal, A.V. Sapre. Effect of solvent polarity on the aggregation of fullerenes: a comparison between $\mathrm{C}_{60}$ and $\mathrm{C}_{70}$. Chem. Phys. Lett. 360, 422 (2002).

44. O.A. Kyzyma, L.A. Bulavin, V.L. Aksenov, T.V. Tropin, M.V. Avdeev, M.V. Korobov, S.V. Snegir, L. Rosta. Aggregation in $\mathrm{C}_{60} / \mathrm{NMP}, \mathrm{C}_{60} / \mathrm{NMP} /$ water and $\mathrm{C}_{60} / \mathrm{NMP} /$ toluene mixtures. Fullerenes, Nanotub. Carbon Nanostruct. 16, 610 (2008).

45. N. Jargalan, T.V. Tropin, M.V. Avdeev, V.L. Aksenov. Investigation and modeling of evolution of $\mathrm{C}_{60} / \mathrm{NMP}$ solution UV-Vis spectra. Nanosyst. Physics, Chem. Math. 7, 99 (2016).

46. M. Alf'e, R. Barbella, A. Bruno, P. Minutolo, A. Ciajolo. Solution behaviour of $\mathrm{C}_{60}$ fullerene in N-methylpyrrolidinone/toluene mixtures. Carbon 43, 665 (2005).

47. T.V. Nagorna, O.A. Kyzyma, L.A. Bulavin, D. Chudoba, V.M. Garamus, M.V. Avdeev, V.L. Aksenov. Specifics of $\mathrm{C}_{60}$ fullerene cluster formation in a solvent mixture of toluene and N-methyl-2-pyrollidone. J. Surf. Investig. 12, 872 (2018).

48. R.G. Alargova, S. Deguchi, K. Tsujii. Stable colloidal dispersions of fullerenes in polar organic solvents. J. Am. Chem. Soc. 123, 10460 (2001).

49. Z. Meng, S.M. Hashmi, M. Elimelech. Aggregation rate and fractal dimension of fullerene nanoparticles via simultane- 
ous multiangle static and dynamic light scattering measurement. J. Colloid Interface Sci. 392, 27 (2013).

50. T.V. Tropin, M.V. Avdeev, O.A. Kyzyma, V.L. Aksenov. Nucleation theory models for describing kinetics of cluster growth in $\mathrm{C}_{60} / \mathrm{NMP}$ solutions. Phys. Status Solidi B 247, 3022 (2010).

51. T.V. Tropin, M.V. Avdeev, O.A. Kyzyma, R.A. Yeremin, N. Jargalan, M.V. Korobov, V.L. Aksenov. Towards description of kinetics of dissolution and cluster growth in $\mathrm{C}_{60}$ /NMP solutions. Phys. Status Solidi $B$ 248, 2728 (2011).

52. T.V. Tropin, N. Jargalan, M.V. Avdeev, O.A. Kyzyma, R.A. Eremin, D. Sangaa, V.L. Aksenov. Kinetics of cluster growth in polar solutions of fullerene: Experimental and theoretical study of $\mathrm{C}_{60} / \mathrm{NMP}$ solution. J. Mol. Liq. 175, 4 (2012).

53. T.V. Tropin, V.L. Aksenov. Theoretical study of the effect of decrease of cluster sizes on dilution of a solution with water. J. Exp. Theor. Phys. 128, 274 (2019).

54. T.V. Tropin, M.V. Avdeev, V.L. Aksenov. Modeling of the evolution of the cluster-size distribution functions in polar fullerene $\mathrm{C}_{60}$ solutions. J. Surf. Investig. X-Ray, Synchrotron Neutron Tech. 13, 82 (2019).

55. V.L. Aksenov, M.V. Avdeev, T.V. Tropin, V.B. Priezzhev, J.W.P. Schmelzer. Cluster growth and dissolution of fullerenes in non-polar solvents. J. Mol. Liq. 127, 142 (2006).

56. V.L. Aksenov, T.V. Tropin, M.V. Avdeev, V.B. Priezzhev, J.W.P. Schmelzer. Kinetics of cluster growth in fullerene molecular solutions. Phys. Part. Nucl. 36, S52 (2005).

57. T.O. Kyrey, O.A. Kyzyma, M.V. Avdeev, T.V. Tropin, M.V. Korobov, V.L. Aksenov, L.A. Bulavin. Absorption characteristics of fullerene $\mathrm{C}_{60}$ in N-methyl-2pirrolidone/toluene mixture. Fullerenes, Nanotub. Carbon Nanostruct. 20, 341 (2012).

58. T.V. Tropin, T.O. Kyrey, O.A. Kyzyma, A.V. Feoktistov, M.V. Avdeev, L.A. Bulavin, L. Rosta, V.L. Aksenov. Experimental investigation of $\mathrm{C}_{60} / \mathrm{NMP} /$ toluene solutions by $\mathrm{UV}$-vis spectroscopy and small angle neutron scattering. J. Surf. Investig. X-Ray, Synchrotron Neutron Tech. 7, 5 (2013).

59. L.A. Bulavin, Y. Prylutskyy, O. Kyzyma, M. Evstigneev, U. Ritter, P. Scharff. Self-organization of pristine $\mathrm{C}_{60}$ fullerene and its complexes with chemotherapy drugs in aqueous solution as promising anticancer agents. Modern Problems of Molecular Physics, edited by L.A. Bulavin, A.V. Chalyi (Springer, 2018) Chap. 1.

60. Y.I. Prylutskyy, V.V. Cherepanov, V.V. Kostjukov, M.P. Evstigneev, O.A. Kyzyma, L.A. Bulavin, O. Ivankov, N.A. Davidenko, U. Ritter. Study of the complexation between Landomycin $\mathrm{A}$ and $\mathrm{C}_{60}$ fullerene in aqueous solution. $R S C A d v$. 6, 81231 (2016).

61. S. Andreev, D. Purgina, E. Bashkatova, A. Garshev, A. Maerle, I. Andreev, N. Osipova, N. Shershakova, M. Khaitov. Study of fullerene aqueous dispersion prepared by novel dialysis method: Simple way to fullerene aqueous solution. Fullerenes, Nanotub. Carbon Nanostruct. 23, 792 (2015).

62. O.A. Kyzyma, M.V. Avdeev, O.I. Bolshakova, P. Melentev, S.V. Sarantseva, O.I. Ivankov, M.V. Korobov, I.V. Mikheev, T.V. Tropin, M. Kubovcikova, P. Kopcansky, V.F. Korolovych, V.L. Aksenov, L.A. Bulavin. State of aggregation and toxicity of aqueous fullerene solutions. Appl. Surf. Sci. 483, 69 (2019).

Received 30.03.2020

T.В. Тропін, Н. Джаргалан,

М.В. Авдєєв, В.Л. Аксъонов

ДОСЛІДЖЕННЯ ЗРОСТАННЯ

КЛАСТЕРІВ У РОЗЧИНАХ ФУЛЕРЕНІВ $\mathrm{C}_{60}$

$\mathrm{P}$ е $з$ ю м е

Фулерени утворюють кластери в різних розчинах. У цій роботі представлено короткий огляд та деякі результати в галузі досліджень структури та кінетики кластерів, що виникають у розчинах $\mathrm{C}_{60}$. Підкреслюється загальний характер цього явища для фулеренів та обговорюються механізми, що відповідають за формування та зростання кластерів. Ми розрізняємо різні типи розчинників фулерену за механізмом агрегаціі. Наведено кінетику росту кластерів, виміряну за допомогою динамічного розсіювання світла. Коротко обговорюється складна структура кластерів у різних розчинах. 